\title{
HYDROGEN BOND INDUCED ASSEMBLY AND CRYSTAL STRUCTURES OF DIOXOVANADIUM(V) COMPLEXES WITH SCHIFF BASES
}

\author{
SHI-YONG LIU ${ }^{1, *}$, YU-PING MA', ZHONG-LU YOU ${ }^{2}$ \\ ${ }^{I}$ College of Chemistry \& Pharmacy, Taizhou University, Taizhou Zhejiang 317000, P. R. China \\ ${ }^{2}$ Department of Chemistry, Liaoning Normal University, Dalian 116029, P. R. China
}

(Received: June 30, 2010 - Accepted: March 22, 2011)

\begin{abstract}
Two new dioxovanadium(V) complexes, $\left[\mathrm{VO}_{2} \mathrm{~L}^{1}\right](\mathbf{1})$ and $\left[\mathrm{VO}_{2} \mathrm{~L}^{2}\right]_{2}(\mathbf{2})$, where $\mathrm{L}^{1}$ and $\mathrm{L}^{2}$ are the deprotonated forms of 4-chloro-2-[(2-piperidin-1-ylethylimino) methyl]phenol and 2-ethoxy-6-[(2-ethylaminoethylimino)methyl]phenol, respectively, have been synthesized and characterized by i.r. spectra and single crystal $\mathrm{X}$-ray diffraction. Complex (1) is a mononuclear dioxovanadium complex, with the $\mathrm{V}$ atom five-coordinate in a distorted square pyramidal geometry. Complex (2) is a dinuclear dioxovanadium complex, with the $\mathrm{V}$ atom six-coordinate in an octahedral geometry. The V $\cdots \mathrm{V}$ distance is 3.096(2) $\AA$. The hydrogen bonds among the Schiff base ligands can influence the structures of the vanadium complexes.
\end{abstract}

Keywords: Synthesis; vanadium complex; Schiff base; X-ray structure analysis.

\section{INTRODUCTION}

A wide number of studies have focused on the Schiff bases and their metal complexes in the fields of coordination chemistry, biological chemistry, and material sciences. ${ }^{1-4}$ In the past few decades, the vanadium complexes have been found to have interesting biological activities such as normalizing the high blood glucose levels and acting as models of haloperoxidases. ${ }^{5-11}$ It has been known that there exists trigonal bipyramidal vanadium within the phosphatemetabolizing enzyme. ${ }^{12,13}$ Mokry and co-workers reported that the steric bulk of the substituent of the benzene ring can be used to modify the coordination geometry and/or number of vanadium atoms by preventing dimerization pathways..$^{14}$ To further explore the role in the synthesis of such complexes, in this paper, two new dioxovanadium $(\mathrm{V})$ complexes, $\left[\mathrm{VO}_{2} \mathrm{~L}^{1}\right](\mathbf{1})$ and $\left[\mathrm{VO}_{2} \mathrm{~L}^{2}\right]_{2}$ (2), where $\mathrm{L}^{1}$ and $\mathrm{L}^{2}$ are the deprotonated forms of 4-chloro-2-[(2-piperidin-1ylethylimino)methyl]phenol $\left(\mathrm{HL}^{1}\right)$ and 2-ethoxy-6-[(2-ethylaminoethylimino) methyl]phenol $\left(\mathrm{HL}^{2}\right)$, respectively, were synthesized and characterized.

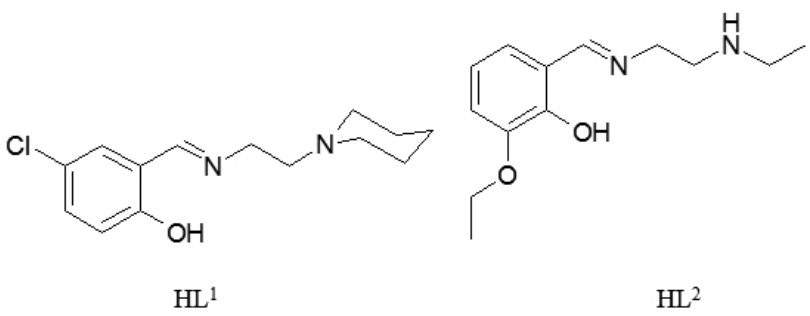

Scheme 1: $\mathrm{HL}^{1}$ and $\mathrm{HL}^{2}$

\section{EXPERIMENTAL}

General: All chemicals used were commercially available with AR grade. Elemental analyses (CHN) were performed using a Perkin-Elmer 240 elemental analyzer. The IR spectra were measured with a Nicolet FT-IR 170SX spectrophotometer using $\mathrm{KBr}$ pellets in the $4000-400 \mathrm{~cm}^{-1}$ region. The Schiff bases $\mathrm{HL}^{1}$ and $\mathrm{HL}^{2}$ were prepared according to the literature method. ${ }^{15}$
Synthesis of the Complex [VO $\left.L^{1}\right]$ (1): A methanol solution $(5 \mathrm{ml})$ of $\mathrm{VO}(\mathrm{acac})_{2}(0.1 \mathrm{mmol}, 26.5 \mathrm{mg})$ was added to a methanol solution $(10 \mathrm{ml})$ of $\mathrm{HL}^{1}(0.1 \mathrm{mmol}, 26.7 \mathrm{mg})$ under stirring. The mixture was stirred at room temperature for $30 \mathrm{~min}$ to give a yellow solution. The resulting solution was allowed to stand in air for a few days. The yellow block-shaped crystals suitable for X-ray single crystal diffraction were formed at the bottom of the vessel. The isolated product was washed with cold methanol, and dried in air. Yield: $62 \%$. Selected i.r. data $\left(\mathrm{KBr}, \mathrm{cm}^{-1}\right): 1631\left(v_{\mathrm{C}=\mathrm{N}}\right), 932,833\left(v_{\mathrm{v}=0}\right)$.

Synthesis of the Complex $\left[\mathrm{VO}_{2} \mathrm{~L}^{2}\right]_{2}$ (2): A methanol solution $(5 \mathrm{ml})$ of $\mathrm{VO}(\mathrm{acac})_{2}(0.1 \mathrm{mmol}, 26.5 \mathrm{mg})$ was added to a methanol solution $(10 \mathrm{ml})$ of $\mathrm{HL}^{2}(0.1 \mathrm{mmol}, 23.6 \mathrm{mg})$ under stirring. The mixture was stirred at room temperature for $30 \mathrm{~min}$ to give a yellow solution. The resulting solution was allowed to stand in air for a few days. The yellow block-shaped crystals suitable for X-ray single crystal diffraction were formed at the bottom of the vessel. The isolated product was washed with cold methanol, and dried in air. Yield: $45 \%$. Selected i.r. data $\left(\mathrm{KBr}, \mathrm{cm}^{-1}\right): 1625\left(v_{\mathrm{C}=\mathrm{N}}\right), 933,835\left(v_{\mathrm{V}=\mathrm{O}}\right)$.

X-ray Structure Analysis: Diffraction intensities for the complex were collected at 298(2) K using a Bruker SMART 1000 CCD area-detector with MoKa radiation $(1=0.71073 \AA)$. The collected data were reduced using the SAINT program, ${ }^{16}$ and empirical absorption corrections were performed using the SADABS program. ${ }^{17}$ The structure was solved by direct methods and refined against $F^{2}$ by full-matrix least-squares methods using the SHELXTL package. ${ }^{18}$ All of the non-hydrogen atoms were refined anisotropically. H2 and $\mathrm{H} 4$ atoms in (2) were located from a difference Fourier map and refined isotropically, with N-H distances restrained to $0.90(1) \AA$, and with $U$. $(\mathrm{H})$ set to $0.08 \AA^{2}$. Other $\mathrm{H}$ atoms in the complexes were placed in calculated positions and constrained to ride on their parent atoms. The crystallographic data for the complexes are summarized in Table 1. Selected bond lengths and angles are listed in Table 2. 
Table 1 Crystal data, data collection and structure refinement for the complexes.

\begin{tabular}{|l|l|l|}
\hline & $(\mathbf{1})$ & $(\mathbf{2})$ \\
\hline Formula & $\mathrm{C}_{14} \mathrm{H}_{18} \mathrm{ClN}_{2} \mathrm{O}_{3} \mathrm{~V}$ & $\mathrm{C}_{26} \mathrm{H}_{38} \mathrm{~N}_{4} \mathrm{O}_{8} \mathrm{~V}_{2}$ \\
\hline$M_{\mathrm{r}}$ & 348.7 & 636.5 \\
\hline Crystal shape/colour & Block/yellow & Block/yellow \\
\hline Crystal system & Monoclinic & Monoclinic \\
\hline Space group & $P 2_{1} / n$ & $P 2_{1}$ \\
\hline$a / \AA$ & $6.328(2)$ & $6.9082(15)$ \\
\hline$b / \AA$ & $22.281(7)$ & $16.890(4)$ \\
\hline$c / \AA$ & $10.684(3)$ & $12.520(3)$ \\
\hline$\square /{ }^{\circ}$ & $90.632(3)$ & $104.889(3)$ \\
\hline$V / \AA^{3}$ & $1506.3(8)$ & $1411.8(6)$ \\
\hline $\mathbf{Z}$ & 4 & 2 \\
\hline$T / \mathrm{K}$ & $298(2)$ & $298(2)$ \\
\hline$D_{c} / \mathrm{g}$ cm$^{-3}$ & 1.538 & 1.497 \\
\hline$F(000)$ & 720 & 664 \\
\hline$\square / m^{-1}($ Mo-K $\alpha)$ & 0.846 & 0.717 \\
\hline$T_{\min }$ & 0.785 & 0.852 \\
\hline$T_{\max }$ & 0.829 & 0.882 \\
\hline Reflections/parameters & $3267 / 190$ & $5691 / 371$ \\
\hline Independent reflections & 2297 & 4078 \\
\hline Restraints & 0 & 3 \\
\hline Goodness of fit on $F^{2}$ & 1.087 & 0.990 \\
\hline$R_{1}, w R_{2}[I \square 2 \sigma(I)]^{a}$ & 0.04490 .1076 & 0.04810 .0823 \\
\hline$R_{1}, w R_{2}(\text { all data })^{a}$ & 0.06960 .1175 & 0.07620 .0945 \\
\hline & & \\
\hline & - & \\
\hline & & \\
\hline
\end{tabular}

${ }^{a} R_{1}=\mathrm{a}|| F O|-| F c|| / \mathfrak{a}|F O|, w R_{2}=\left[\mathfrak{a} w\left(F O^{2}-F c^{2}\right)^{2} / \mathfrak{a} w\left(F O^{2}\right)^{2}\right]^{1 / 2}, w_{1}=\left[\sigma^{2} F O^{2}+\right.$ $\left.\left(0.0526\left(F O^{2}+2 F c^{2}\right) / 3\right)^{2}+0.0825\left(F O^{2}+2 F c^{2}\right) / 3\right]^{-1}, w_{2}=\left[\sigma^{2} F O^{2}+\left(0.0291\left(F O^{2}\right.\right.\right.$ $\left.\left.\left.+2 F c^{2}\right) / 3\right)^{2}\right]^{-1}$.

Table 2 Selected bond lengths $(\AA)$ and bond angles $\left({ }^{\circ}\right)$ for the complexes.

\begin{tabular}{|c|c|c|c|}
\hline (1) & & & \\
\hline V1-O1 & $1.925(2)$ & V1-O2 & $1.606(2)$ \\
\hline V1-O3 & $1.614(2)$ & V1-N1 & $2.133(2)$ \\
\hline V1-N2 & $2.195(2)$ & & \\
\hline $\mathrm{O} 2-\mathrm{V} 1-\mathrm{O} 3$ & $110.15(12)$ & O2-V1-O1 & $101.16(10)$ \\
\hline O3-V1-O1 & 97.91(10) & O2-V1-N1 & 116.99(9) \\
\hline O3-V1-N1 & $131.95(11)$ & O1-V1-N1 & $82.15(8)$ \\
\hline $\mathrm{O} 2-\mathrm{V} 1-\mathrm{N} 2$ & $95.51(9)$ & O3-V1-N2 & $91.21(9)$ \\
\hline O1-V1-N2 & $156.85(9)$ & N1-V1-N2 & $75.99(8)$ \\
\hline \multicolumn{4}{|l|}{ (2) } \\
\hline V1-O1 & $1.924(3)$ & V1-O5 & $1.666(3)$ \\
\hline V1-O6 & $1.606(3)$ & V1-O7 & $2.315(3)$ \\
\hline V1-N1 & $2.183(4)$ & V1-N2 & $2.180(3)$ \\
\hline V2-O3 & $1.921(3)$ & V2-O5 & $2.298(3)$ \\
\hline V2-O7 & $1.672(3)$ & V2-O8 & $1.602(3)$ \\
\hline V2-N3 & $2.167(4)$ & V2-N4 & $2.165(4)$ \\
\hline O6-V1-O5 & $105.78(15)$ & O6-V1-O1 & $102.08(15)$ \\
\hline O5-V1-O1 & $97.47(13)$ & O6-V1-N2 & $95.74(15)$ \\
\hline O5-V1-N2 & $95.78(14)$ & O1-V1-N2 & $153.93(13)$ \\
\hline O6-V1-N1 & $92.01(16)$ & O5-V1-N1 & $161.37(15)$ \\
\hline O1-V1-N1 & $83.83(13)$ & N2-V1-N1 & $76.62(13)$ \\
\hline O6-V1-O7 & $171.60(13)$ & O5-V1-O7 & $78.69(12)$ \\
\hline O1-V1-O7 & $84.14(11)$ & $\mathrm{N} 2-\mathrm{V} 1-\mathrm{O} 7$ & $76.57(13)$ \\
\hline N1-V1-O7 & $82.97(12)$ & & \\
\hline N2-H2 & $0.90(1)$ & $\mathrm{H} 2 \cdots \mathrm{O} 3$ & $2.15(3)$ \\
\hline $\mathrm{N} 2 \cdots \mathrm{O} 3$ & $2.98(1)$ & $\mathrm{N} 2-\mathrm{H} 2 \cdots \mathrm{O} 3$ & $153(5)$ \\
\hline N4-H4 & $0.90(1)$ & $\mathrm{H} 4-\mathrm{O} 1$ & $2.22(3)$ \\
\hline $\mathrm{N} 4 \cdots \mathrm{O} 1$ & 3.01(1) & N4-H4 $\cdots \mathrm{O} 1$ & $146(5)$ \\
\hline N4-H4 & $0.90(1)$ & H4-O5 & $2.39(5)$ \\
\hline $\mathrm{N} 4 \cdots \mathrm{O} 5$ & $2.89(1)$ & N4-H4 $\cdots$ O5 & $115(4)$ \\
\hline
\end{tabular}

\section{RESULTS AND DISCUSSION}

The Schiff bases $\mathrm{HL}^{1}$ and $\mathrm{HL}^{2}$ were prepared via the reaction of equimolar quantities of aldehydes with primary amines in methanol. It is notable that only one copper(II) complex derived from $\mathrm{HL}^{1},{ }^{15}$ and one nickel(II) and one zinc(II) complexes derived from $\mathrm{HL}^{2}{ }^{19,20}$ have been reported so far. The two complexes in this paper were readily synthesized according to the standard procedure (Scheme 2), crystallized as yellow crystals, which are stable in air at room temperature. The crystals of the complexes are soluble in DMSO, DMF, $\mathrm{MeCN}, \mathrm{MeOH}$ and $\mathrm{EtOH}$, insoluble in water.<smiles>O=S1(=O)Oc2ccc(Cl)cc2CN1CCN1CCN(CCO)CC1</smiles>

(1)

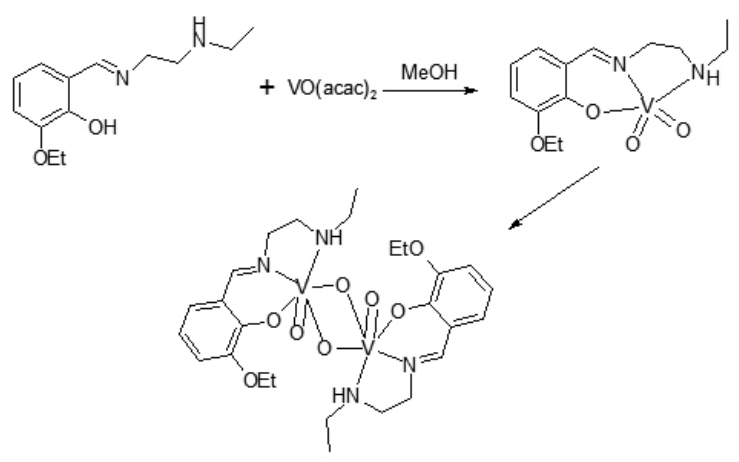

(2)

Scheme 2: The synthesis of the complexes.

Structure Description of the Complex (1): The molecular structure of the complex (1) is shown in Figure 1. The V atom is five-coordinate in a distorted square pyramidal geometry. The basal plane is composed of the phenolate $\mathrm{O}$, imine $\mathrm{N}$ and amine $\mathrm{N}$ atoms of the Schiff base ligand $\mathrm{L}^{1}$, and an oxo ligand $\mathrm{O} 3$. The apical position is occupied by a second oxo ligand, $\mathrm{O} 2$. The $\mathrm{V}$ atom lies 0.501(2) $\AA$ from the mean plane of the basal atoms, in the direction of the apical oxo ligand. The coordinate bond lengths in the complex are comparable with those observed in other similar vanadium complexes. ${ }^{21-23}$ The $\tau$ value for the complex is 0.415 , indicating a severely distorted square pyramidal coordination. ${ }^{24}$

In the crystal structure of (1), molecules are linked through intermolecular $\mathrm{C}-\mathrm{H} \cdots \mathrm{O}$ hydrogen bonds, forming chains running along the $c$ axis, as shown in Figure 2.

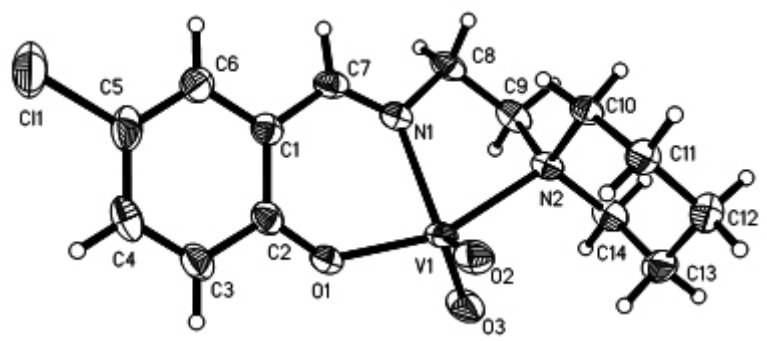

Figure 1 Molecular structure of the complex (1) at $30 \%$ probability displacement. 


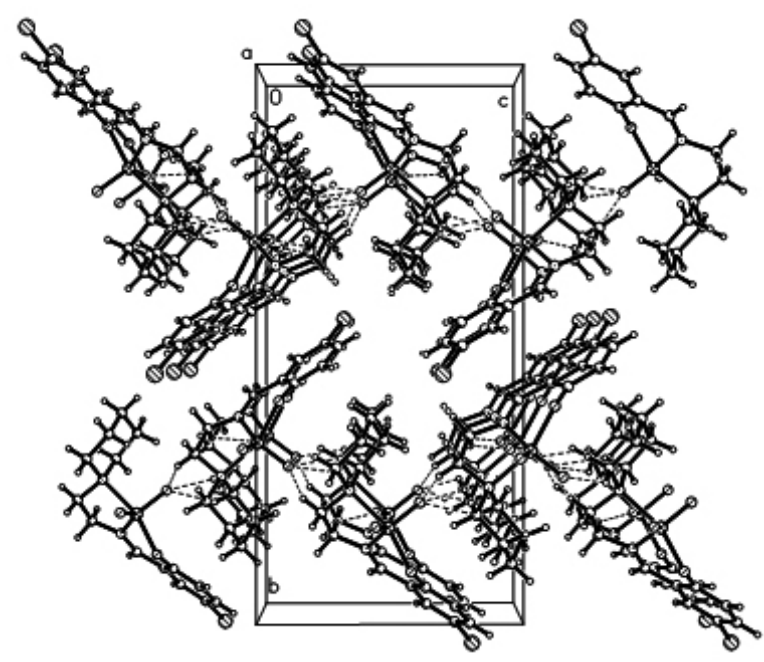

Figure 2 Molecular packing of the complex (1), viewed along the $a$ axis. Intermolecular $\mathrm{C}-\mathrm{H} \cdots \mathrm{O}$ hydrogen bonds are shown as dashed lines.

Structure Description of the Complex (2): The molecular structure of the complex (2) is shown in Figure 3. The compound is a dinuclear dioxovanadium complex. The $\mathrm{V} \cdots \mathrm{V}$ distance is 3.096(2) $\AA$. Each $\mathrm{V}$ atom in the complex is six-coordinated through three bonds to oxo groups and through bonds to the tridentate Schiff base ligand $\mathrm{L}^{2}$, forming an octahedral geometry. The distances between atoms V1 and O6, and atoms V2 and O8 are 1.606(2) and 1.602(2) $\AA$, indicating they are typical $\mathrm{V}=\mathrm{O}$ bonds. The $\mathrm{O} 5$ and $\mathrm{O} 7$ are two bridging atoms, with O5 strongly coordinated to V1 [1.666(2) Å], and O7 strongly coordinate to V2 $[1.672(2) \AA]$. The coordinate bond lengths are comparable to those observed in (1), and other similar vanadium complexes. ${ }^{25-27}$ The distortion of the octahedral coordination can be observed by the coordinate bond angles, ranging from $76.5(2)$ to $106.8(2)^{\circ}$ for the perpendicular angles, and from $153.9(2)$ to $173.3(2)^{\circ}$ for the diagonal angles. There form two intramolecular $\mathrm{N}-\mathrm{H} \cdots \mathrm{O}$ hydrogen bonds in the molecule of the complex.

In the crystal structure of (2), molecules are linked through intermolecular $\mathrm{C}-\mathrm{H} \cdots \mathrm{O}$ hydrogen bonds, forming a three-dimensional network, as shown in Figure 4.

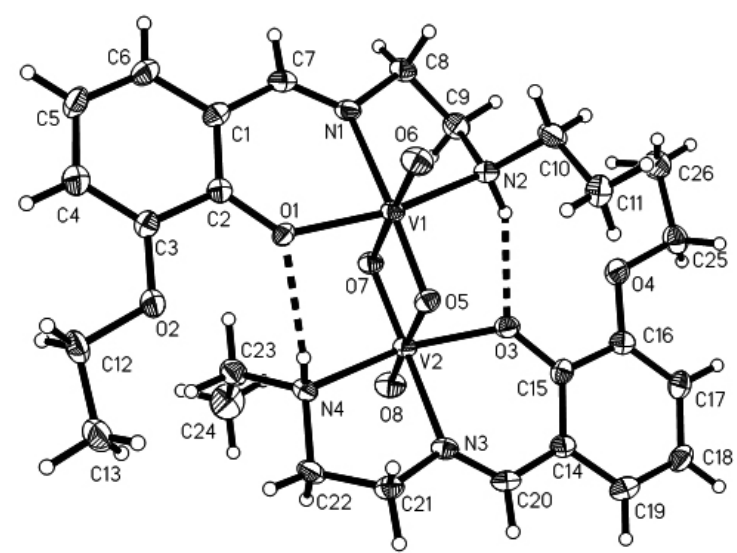

Figure 3 Molecular structure of the complex (2) at 30\% probability displacement.

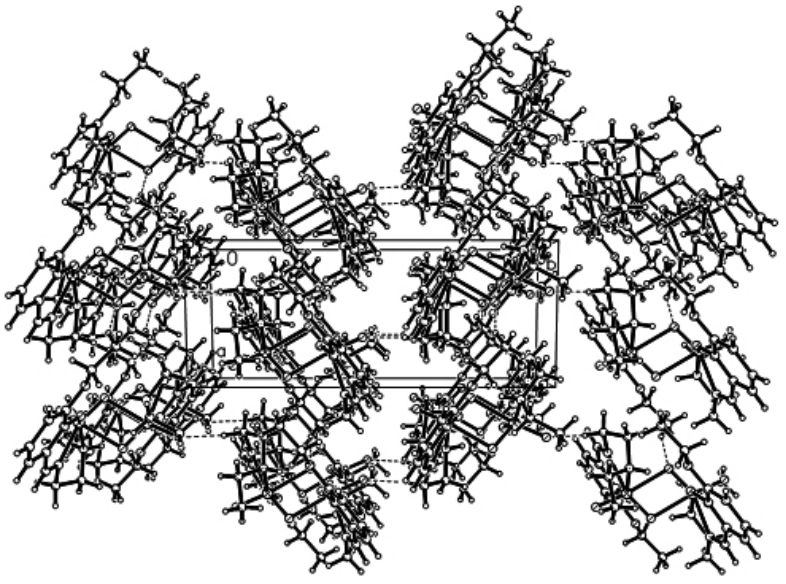

Figure 4 Molecular packing of the complex (2), viewed along the $c$ axis. Intermolecular $\mathrm{C}-\mathrm{H} \cdots \mathrm{O}$ hydrogen bonds are shown as dashed lines.

\section{CONCLUSION}

In the present paper, two new dioxovanadium complexes have been synthesized and characterized by X-ray diffraction. The Schiff bases 4-chloro-2-[(2-piperidin-1-ylethylimino)methyl]phenol and 2-ethoxy-6-[(2ethylaminoethylimino)methyl]phenol coordinate to the $\mathrm{V}$ atoms through the phenolate $\mathrm{O}$, imine $\mathrm{N}$ and amine $\mathrm{N}$ atoms. The $\mathrm{N}-\mathrm{H} \cdots \mathrm{O}$ hydrogen bonds among the Schiff base ligands seem to be the primary factor to influence the structures of the vanadium complexes.

\section{Supplementary material}

Supplementary material CCDC - 780273 for (1) and 780274 for (2) contain the supplementary crystallographic data for this paper. These data can be obtained free of charge at http://www.ccdc.cam.ac.uk/const/retrieving.html or from the Cambridge Crystallographic Data Centre (CCDC), 12 Union Road, Cambridge CB2 1EZ, UK; fax: +44(0)1223-336033 or e-mail: deposit@ccdc. cam.ac.uk

\section{ACKNOWLEDGEMENTS}

We acknowledge the Taizhou University for funding this work.

\section{REFERENCES}

1. L. Shi, W.-J. Mao, Y. Yang, H.-L. Zhu, J. Coord. Chem. 62, 3471, (2009).

2. K. Cheng, Q.-Z. Zheng, Y. Qian, L. Shi, J. Zhao, H.-L. Zhu, Bioorg. Med. Chem. 17, 7861, (2009).

3. Z.-L. You, D.-H. Shi, C. Xu, Q. Zhang, H.-L. Zhu, Eur. J. Med. Chem. 43, 862, (2008)

4. H.-J. Kim, W. Kim, A.J. Lough, B.M. Kim, J. Chin, J. Am. Chem. Soc. 127, 16676, (2005).

5. G.R. Willsky, A.B. Goldfine, P.J. Kostyniak, J.H. McNeill, L.Q. Yang, H.R. Khan, D.C. Crans, J. Inorg. Biochem. 85, 33, (2001).

6. C. Orvig, P. Caravan, L. Gelmini, N. Glover, F.G. Herring, H. Li, J.H. McNeill, S.J. Rettig, I.A. Setyawati, J. Am. Chem. Soc. 117, 12759, (1995).

7. K.H. Thompson, J.H. McNeill, C. Orvig, Chem. Rev. 99, 2561, (1999)

8. M. Melchior, K.H. Thompson, J.M. Jong, S.J. Rettig, E. Shuter, V.G. Yuen, Y. Zhou, J.H. McNeill, C. Orvig, Inorg. Chem. 38, 2288, (1999).

9. A. Sheela, S.M. Roopan, R. Vijayaraghavan, Eur. J. Med. Chem. 43, 2206, (2008).

10. Y. Shechter, I. Goldwaser, M. Mironchik, M. Fridkin, D. Gefel, Coord Chem. Rev. 237, 3, (2003).

11. M.J. Pereira, E. Carvalho, J.W. Eriksson, D.C. Crans, M. Aureliano, J. Inorg. Biochem. 103, 1687, (2009).

12. B. Borah, C.W. Chen, W. Egan, M. Miller, A. Wlodawer, J.S. Cohen, Biochemistry 24, 2058, (1985).

13. A. Wlodawer, M. Miller, L. Sjolin, Proc. Natl. Acad. Sci. U.S.A. 89, 3628, (1983).

14. L.M. Mokry, C.J. Carrano, Inorg. Chem. 32, 6119, (1993). 
15. C.-Y. Wang, J.-Y. Ye, C.-Y. Lv, W.-Z. Lan, J.-B. Zhou, J. Coord. Chem. 62, 2164, (2009).

16. Bruker, SMART (Version 5.628) and SAINT (Version 6.02); Bruker AXS Inc: Madison, Wisconsin, USA, (1998).

17. G.M. Sheldrick, SADABS Program for Empirical Absorption Correction of Area Detector, University of Göttingen, Germany, (1996).

18. G.M. Sheldrick, SHELXTL V5.1. Software Reference Manual; Bruker AXS, Inc: Madison, Wisconsin, USA, (1997).

19. X.-W. Zhu, X.-Z. Yang, Acta Crystallogr. E64, m1096, (2008).

20. H.-R. Guo, Acta Crystallogr. E64, m1288, (2008).

21. M.-J. Xie, Y.-S. Ping, L.-D. Zheng, J.-Z. Hui, C. Peng, Acta Crystallogr. E60, m1382, (2004).
22. E. Kwiatkowski, G. Romanowski, W. Nowicki, M. Kwiatkowski, K. Suwinska, Polyhedron 22, 1009, (2003).

23. I.C. Mendes, L.M. Botion, A.V.M. Ferreira, E.E. Castellano, H. Beraldo, Inorg. Chim. Acta 362, 414, (2009).

24. A.W. Addison, T.N. Rao, J. Reedijk, J. van Rijn, G.C. Verschoor, J. Chem. Soc. Dalton Trans. 1349, (1984).

25. L.-Z. Li, T. Xu, D.-Q. Wang, H.-W. Ji, Chinese J. Inorg. Chem. 20, 236, (2004).

26. C.A. Duncan, E.P. Copeland, I. Kahwa, A. Quick, D.J. Williams, J. Chem. Soc. Dalton Trans. 917, (1997).

27. E. Kwiatkowski, G. Romanowski, W. Nowicki, M. Kwiatkowski, Polyhedron 25, 2809, (2006). 